\title{
The European Innovative Medicines Initiative: Progress to Date
}

\author{
Jean-Emmanuel Faure ${ }^{1} \cdot$ Tomasz Dyląg $^{1} \cdot$ Irene Norstedt $^{1} \cdot$ Line Matthiessen $^{1}$
}

Published online: 19 July 2018

(c) The Author(s) 2018

\begin{abstract}
The Innovative Medicines Initiative is a public-private partnership between the European Union and the pharmaceuticals industry that was established in 2008, with an overall budget of $€ 5.3$ billion from 2008 until 2024. The objective of the initiative is to boost pharmaceutical innovation in Europe and speed up the development of innovative medicines, vaccines and medical technologies, in particular in areas with high unmet needs. This article discusses the objectives of the initiative, its governance and main results and impact. The initiative has proved to be a unique platform for multi-stakeholder collaborations across Europe. It has contributed to the acceleration of the development process for medicines, from drug discovery to clinical development. The initiative has made important steps towards accessing and using real-world evidence for pharmaceutical research and development, and for healthcare decision-making. Several projects have contributed to a better understanding of the causes of diseases, and some are already delivering results, such as a vaccine against Ebola virus. The initiative has also significantly contributed to building capacity and resources for open use by the broader research and innovation community.
\end{abstract}

\section{Key Points}

The Innovative Medicines Initiative aims at boosting pharmaceutical innovation in Europe and ultimately improving health by speeding up the development of innovative medicines, vaccines and medical technologies, particularly in areas where there is an unmet medical need.

The initiative has proved to be a unique platform for multi-stakeholder collaborations across Europe.

It has contributed to the acceleration of the medicines' development process, from drug discovery to clinical development.

Electronic supplementary material The online version of this article (https://doi.org/10.1007/s40290-018-0241-y) contains supplementary material, which is available to authorized users.

Jean-Emmanuel Faure

jean-emmanuel.faure@ec.europa.eu

1 Research and Innovation, European Commission, 1049 Brussels, Belgium

\section{Rationale}

Horizon 2020 is the European Union (EU) Framework Programme for funding research and innovation running from 2014 to 2020 [1]. Horizon 2020 is divided into three pillars that support "Excellent Science", "Industrial Leadership" and "Societal Challenges". One of the flagships under the first Societal Challenge for "Health, demographic change and well-being" is the Innovative Medicines Initiative (IMI) [2]. IMI is a Joint Undertaking between the EU and the European Federation of Pharmaceutical Industries Associations (EFPIA) - as well as other industries. It is the world's largest public-private initiative for health research and innovation. The initiative aims at boosting pharmaceutical innovation in Europe and ultimately improving health by speeding up the development of innovative medicines, vaccines and medical technologies, particularly in areas where there is an unmet medical need. The migration of research investments of the pharmaceutical industry out of Europe was one of the drivers for setting up IMI earlier in 2008, under the previous EU Framework Programme for Research and Technological Development (FP7), running from 2007 to 2013. IMI supports collaborative research and innovation projects and builds networks of industrial and academic experts, including non-pharmaceutical industries and small and medium-sized enterprises (SMEs), patient 


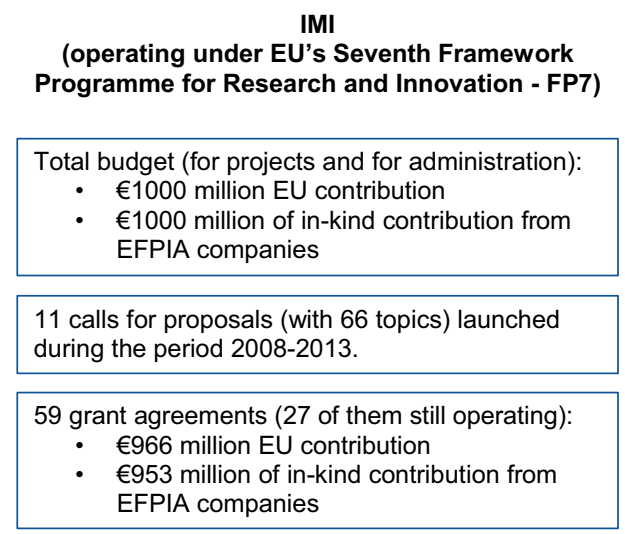

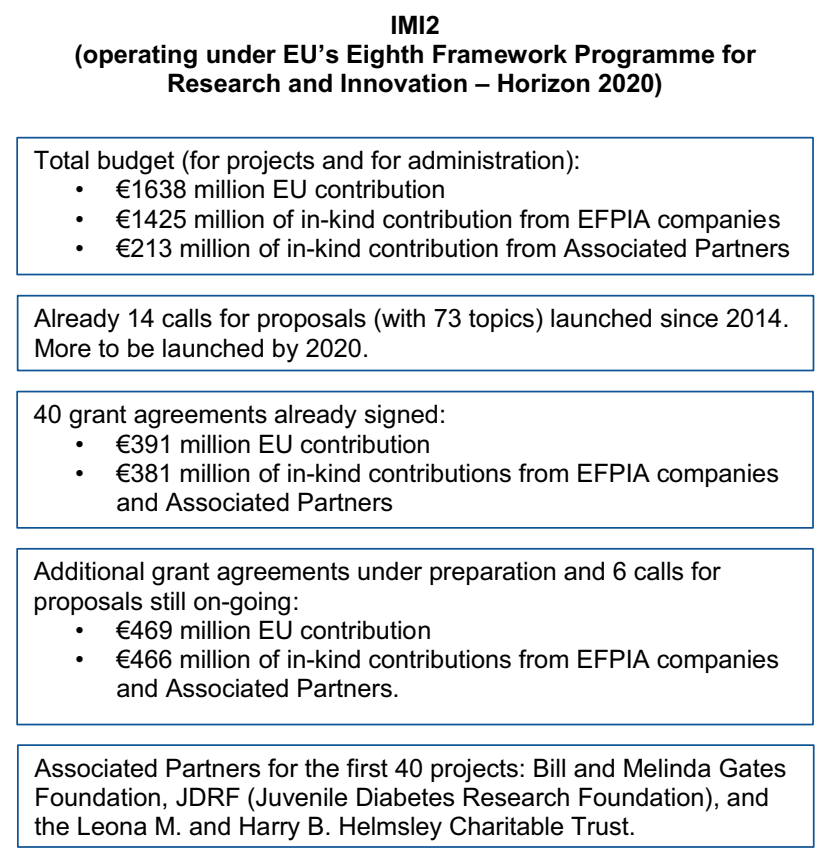

Fig. 1 Budget and state of implementation of the two phases of the Innovative Medicines Initiative (IMI). EFPIA European Federation of Pharmaceutical Industries Associations, EU European Union

organisations, and regulators. With IMI, the EU supports activities of strategic importance for its competitiveness and industrial leadership, and responds to gaps in treating current public health issues as identified by the World Health Organization.

\section{Budget}

The first phase of the IMI took place with calls for proposals already launched between 2008 and 2013 [3] and an overall budget of close to $€ 2$ billion (Fig. 1). EFPIA companies do not receive funding from the EU for their participation in IMI projects, but contribute to the projects with resources mostly in kind (e.g. hours of staff directly working on the projects, subcontracting to clinical research organisations for clinical trials, or other direct costs) and to a limited extent in cash (e.g. a transfer of funds from an EFPIA company to an academic institution within the same project). The second phase, IMI2, was launched in July 2014 [4, 5]. IMI2 is established until 2024 and has an overall budget of $€ 3.3$ billion (Fig. 1). A novelty of IMI2 is the introduction of Associated Partners, which are legal entities other than EFPIA companies willing to support the objectives of IMI2 and to contribute financially. Numerous non-pharmaceutical industries contribute to IMI2. In particular, BioMérieux, Bruker, FujiFilm, GE Healthcare, Medtronic, Nokia, Piramal, and Zeiss, joined as EFPIA partners or as Associated Partners to IMI2 [6].

\section{Objectives}

The objective of the first phase of IMI was to significantly improve the efficiency and effectiveness of the drug development process with the long-term aim that the pharmaceutical sector would produce more effective and safer innovative medicines. This was done, among other approaches, by supporting pre-competitive pharmaceutical research and development in the EU Member States and in countries associated with FP7 [3]. The objectives of the second phase of IMI, IMI2, evolved to address the full spectrum of medical interventions from discovery and development, to understanding the underlying causes of diseases and identifying potential drugs and drug targets, through testing potential drugs for safety and efficacy, to clinical trial design and monitoring the benefits and risks of medicines and vaccines once they are in use. Correspondingly, an important new feature of IMI2 is the integration of Associated Partners to actively involve industries other than those for pharmaceuticals, for example, those involving vaccines, diagnostics, animal health, biomedical imaging or the digital industry, as well as other organisations willing to support the objectives of the initiative, such as charities, for example, Bill and Melinda Gates Foundation and Wellcome Trust [6]. Some of the specific objectives of IMI2 are to increase the success rate of clinical trials of new medicines and vaccines, speed up the earlier stages of drug development, develop 
new treatments for areas of unmet need and new biological markers to diagnose diseases and assess treatments, and improve the drug development process by creating tools to assess the efficacy, safety and quality of medicines [4]. The priority areas for IMI 2 have been laid down in a Strategic Research Agenda [7] and are aligned with those identified in the World Health Organization report "Priority medicines for Europe and the world" [8].

\section{Governance}

IMI2 is governed by a board composed of ten members equally representing the two Founding Members: five from the European Commission, representing the EU, and five from EFPIA, representing the research-based pharmaceutical industry in Europe. The Governing Board is the main decision-making body of IMI2. In particular, it adopts the Annual Work Plans that identify calls for proposals, with call topics from which collaborative projects are being selected by panels of independent experts. Two advisory bodies to the Governing Board have been established: (1) a Scientific Committee with leading experts from a range of fields, who participate in their individual capacities; and (2) a States Representatives Group with members from the EU Member States and the countries associated with Horizon 2020, who represent their national governments. Further advisory bodies, called Strategic Governing Groups (SGGs), have been established in a few strategic areas to ensure the coordination of the work of IMI2 and to make the development of new topics more transparent and effective. As of March 2018, seven SGGs have been established for (1) immunology; (2) diabetes and metabolic disorders; (3) neurodegeneration; (4) translational safety; (5) digital health and patient-centric evidence generation; (6) infections control; and (7) oncology [9]. Each SGG brings together representatives of interested EFPIA companies and Associated Partners, the European Commission, the IMI2 Scientific Committee and the IMI2 Programme Office. The IMI 2 call topics are designed based on ideas stemming from the SGGs, individual EFPIA companies, Associated Partners or individual third parties. They are agreed on by the two Founding Members after consultation with the Scientific Committee and the States Representatives Group.

\section{State of Implementation and Investments}

The state of implementation is summarised in Fig. 1. Together, the two phases of IMI have already committed a total of $€ 2.69$ billion ( $€ 1.36$ billion of EU contributions and $€ 1.33$ billion of EFPIA/Associated Partners contributions), through 59 projects from the first phase of IMI

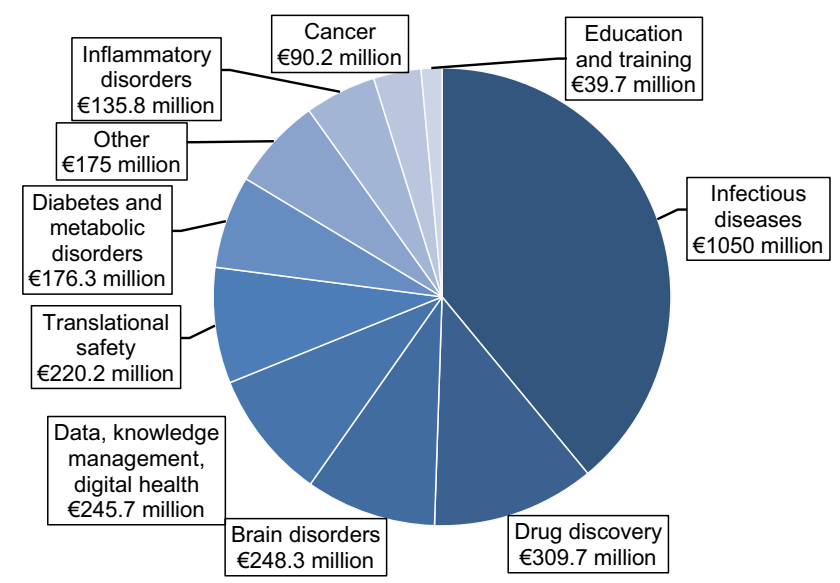

Fig. 2 Distribution per general scientific area of the $€ 2.69$ billion of investments (EU financial contribution and EFPIA/Associated Partners in-kind contributions) already committed in IMI projects (59 projects from the first phase and 40 first projects from the second phase). The category "Other" includes areas such as pulmonary diseases, eye diseases, ageing-associated diseases, drug delivery, and the environmental impact of medicines. The other general scientific areas are specified in more detail in the electronic supplementary material (see online resource 1), notably disease areas, and with lists of projects. EFPIA European Federation of Pharmaceutical Industries Associations, $E U$ European Union, IMI Innovative Medicines Initiative

plus the 40 first IMI 2 projects. The main areas covered are identified in Fig. 2.

Some large-scale programmes, each including several projects, have been launched since the start of IMI. In 2012, IMI launched the world's first major public-private partnership to combat antimicrobial resistance, New Drugs for Bad Bugs (ND4BB). In 2014, IMI reacted urgently to the Ebola crisis in West Africa and launched the Ebola + programme. In 2015, IMI2 launched the Big Data for Better Outcomes (BD4BO) programme to support the evolution towards more outcome-focused healthcare systems in Europe. Additionally, large-scale projects have been launched in 2016 with IMI 2 Call 10, for the creation of a pan-European paediatric clinical trials network and to support personalised medicine approaches in autism spectrum disorders (ASD).

\section{Evaluation of the Initiative and Future Activities}

In 2016, the European Commission asked a group of five independent experts to carry out a final evaluation of the first phase of IMI operating under FP7, as well as an interim evaluation of the ongoing IMI2 initiative (for the period 2014-2016) operating under Horizon 2020. 
Two corresponding reports were published on 6 October 2017 [10, 11], as well as an overall interim assessment of the seven Joint Undertakings ${ }^{1}$ operating under Horizon 2020 [12]. The experts concluded that "the reasons to create a public-private partnership to strengthen the European pharma industry were valid and the goals were justified", and that the partnership had "realised a number of very promising results". The experts, however, recommended that (1) stronger efforts be made to attract and integrate other industries besides pharmaceutical industries in the collaborative projects; (2) more efforts be deployed to attract more SMEs; (3) access to project outcomes be broadened and the sustainability of project results be improved, to increase impact; (4) better Key Performance Indicators of the initiative be developed; and (5) Intellectual Property (IP) policy be reviewed to make it more flexible, allowing negotiations on exclusive rights. In November 2017, the IMI2 Governing Board agreed on an Action Plan addressing these recommendations in IMI2, and actions are now underway. A new framework of Key Performance Indicators has already been adopted, and activities designed specifically to engage more nonpharmaceutical industries and SMEs have been initiated.

\section{Examples of Projects, Results and Impacts}

Measuring the overall impact and return on investment of the initiative is challenging and still premature considering the long timelines of clinical research and development. The experts who evaluated IMI indeed concluded in 2017 that "more time was needed" in order to "realise a measurable socio-economic impact or a measurable impact for patients and their health" [10]. However, as several projects from the IMI first phase are coming to an end, we are beginning to witness and measure important results, outcomes, and some impacts of the initiative.

\subsection{Creating Wide Multi-stakeholder Collaborations}

First of all, IMI has proved successful as a platform for wide multi-stakeholder collaborations bringing together various pharmaceutical companies, SMEs, academic partners, medicines regulatory agencies, and patient organisations across Europe. These collaborations are unique since many of the

\footnotetext{
1 These seven Joint Undertakings are as follows: IMI2 (partnership with the pharmaceuticals industries); Clean Sky 2 (partnership with the aeronautics industries); Shift2Rail (partnership with the rail industries); SESAR (partnership with the air traffic management sector); FCH2 (partnership with the fuel cells and hydrogen industries); BBI (partnership with the bio-based industries); and ECSEL (partnership with the electronics components and systems industries).
}

involved companies are market competitors and had little to no incentive to collaborate beforehand. The openness of IMI is exemplified by the inclusion of patient groups (represented in approximately $75 \%$ of relevant IMI projects). Medicines regulatory agencies are also contributing to the initiative. Their contribution as project participants increased from $17 \%$ in IMI 1 projects to $20 \%$ in the first IMI 2 projects. This may be considered as a rather modest participation. However, organisations like the European Medicines Agency (EMA) have limited staff resources. They can participate in only a limited number of IMI projects, but can contribute via other channels such as project advisory boards. The experts who evaluated IMI also pointed out that a close relationship of the regulatory agencies with industry could give rise to a "negative public perception" [11].

The power of these collaborations can be quantified by the analysis of joint project publications. IMI has produced almost 2700 publications during the period 2010-2016 [13], plus an additional $1100+$ articles in 2017 . The average journal impact factor for IMI research published in 2010-2016 is 6.16. The field-normalised citation impact is 2.03 , comparable with the Foundation for the National Institutes of Health (1.96; close to 1900 publications over 2010-2016), the UK Medical Research Council (2.01; close to 34,500 publications over 2010-2016) and the Wellcome Trust (2.05; close to 42,000 publications over 2010-2016), the baseline being 1 for the world (in similar fields). It is also almost twice as high as the EU average of 1.18. Almost two-thirds of all IMI project publications were cross-sectoral, with authors from various sectors (e.g. industry, SMEs, academia), and the publications have high impact as measured by the relative citation impact [13]. Notably, many project networks are maintained after the projects' end.

\subsection{Accelerating Medicines Development}

IMI projects have already developed over 35 new validated drug targets; over 30 new in vitro models and tools; over 300 new in silico (computer-based) models; over 70 new animal models; over 1500 new stem cell lines; a dozen novel imaging techniques; over 300 biomarkers in development, of which more than 130 have been validated, promising better diagnosis and treatment design for patients; and close to 40 cohorts and registries [14]. For example, the eTOX project [15] gathered the available toxicity data to generate in silico models predicting the toxicity of new drug candidates early in the development process. The resource created offers a set of tools for data visualisation and interpretation [16]. Notably, the consortium successfully overcame the intrinsic reluctance of pharmaceutical companies as data owners about sharing their sensitive data. The resulting database is now being used among several industry partners to predict the toxicity of new drug candidates and is commercially 
sustainable. The SAFE-T project [17] has significantly accelerated the identification of biomarkers for the prediction, detection, and monitoring of drug-induced injuries to the liver, kidney, and vascular system, with letters of support received from the EMA as well as from the Food and Drug Administration (FDA). These biomarkers are now being used by industries to assess the safety of drugs under development. As another example, the PRO-Active project [18] developed new patient-centred tools capturing physical activity data in patients with chronic obstructive pulmonary disease (COPD) to help them get more personalised treatments and enjoy more active and productive lives. These patient-reported outcome instruments received a draft qualification opinion from the EMA.

IMI projects are making important steps towards the integration of data derived from patients in real life practice settings (real-world evidence [RWE]) into drug development. The GetReal project demonstrated how new methods of RWE collection and synthesis could be included at the early stage of pharmaceutical $R \& D$ and in the healthcare decision-making process. This multi-stakeholder group tackled the RWE from various angles, among others, by conducting case studies of approximately 1.5 years each, in several disease areas. The consortium also compared the experience of data retrieval from RWE and randomised controlled trials (RCTs). The project outcomes, including a set of best practice recommendations, were made available via a comprehensive series of open-access articles [19, 20]. Related aspects of RWE were tackled by several additional projects such as PRO-Active [18], ADAPT-SMART [21] or RADARCNS [22]. All these efforts aim at enriching the types of data to inform drug development processes and patient management beyond data coming from RCTs.

\subsection{Addressing the Most Challenging Disease Areas}

More than 30 IMI projects have contributed to better understanding the causes of diseases. Several IMI projects are developing new taxonomies of diseases based on molecular mechanisms, instead of purely clinical features, thus helping to develop new ways to prevent or interfere with diseases at an individual or patient subgroup level. The PRECISESADS [23] and AETIONOMY [24] projects are establishing mechanism-based taxonomies for inflammatory and neurodegenerative diseases, respectively, and are expected to facilitate drug development and personalised approaches [25]. The EU-AIMS project [26] contributed to identifying factors and mechanisms underlying ASD [27-30]. The consortium developed the worldwide largest multicentre, multidisciplinary study on ASD [31-33] in order to identify stratification biomarkers. EU-AIMS received letters of support from the EMA on methods used to identify biomarkers to help distinguish distinct subtypes of ASD, making an important contribution to the first EMA guideline on autism. Another project, U-BIOPRED [34], provided a much better understanding of the molecular background of severe asthma, notably at genetic and transcriptomic levels, thanks to in-depth omics analysis, and identified several subtypes of this condition, paving the way for development of new treatments and the facilitation of personalisation of treatment to an individual patient [35-38].

An important outcome of IMI activity is delivering results for patients in particular areas with high unmet needs. The IMI Ebola + programme was launched in response to the Ebola virus disease outbreak of 2014, tackling various research challenges such as vaccine development, storage and transport, clinical trials, as well as diagnostics and treatments. Two projects, EBOVAC1 and EBOVAC2 [39], successfully implemented phase 1 and phase 2 trials for the development of a novel prime-boost preventive vaccine. The final phase 1 data published in March 2017 show that the vaccine regimen induced a durable immune response in all healthy volunteers 1 year after vaccination [40]. A phase 2 trial and phase $2 \mathrm{~B}$ large-scale safety and immunogenicity study are being conducted in parallel. The recently selected EBOVAC3 project aims at supporting the remaining clinical and manufacturing activities required to move towards licensure of the vaccine candidate. Another project, Mofina [41], developed a portable diagnostic device that detects Ebola or related diseases in less than $75 \mathrm{~min}$. This robust diagnostic delivers results in environments where complex laboratory equipment is not available.

\subsection{Strengthening Research Capacity}

Last, IMI projects have already significantly contributed to building capacity and resources in Europe for the broader research and innovation community. This is certainly an important achievement, considering that one of the drivers for setting up IMI in 2008 was to strengthen pharmaceutical research investments in Europe. The ELF project [42], for a European Lead Factory, is a significant example of this sort of result, with hopefully long-lasting impacts. The project established a unique collection of compounds and a screening centre to support industries, academia and SMEs identifying high-quality hits for their drug targets [43]. As of December 2017, the compound library contained more than 500,000 compounds, taking it beyond the goal set at the start of the project. By October 2017, 88 drug targets had already been accepted for screening, for which 51 Qualified Hit Lists have been delivered. Thirtyfive programmes have further progressed these initial hits into the Improved Hit List phase. The COMBACTE-NET project [44] established a European clinical trial network with more than 890 clinical sites in 37 European countries (as of February 2018). This network is capable of quickly 
and reliably recruiting, treating, monitoring and reporting data on the required numbers of patients in multinational trials to find new antimicrobials against resistant bacterial pathogens. The COMBACTE-NET project also established a network of more than 670 microbiology laboratories (as of February 2018) able to give access to high-quality and standardised information on microbial strains. The EUPATI project [45] developed the first European Patients' Academy on therapeutic innovation, with training courses for patients, educational material and an online public library. It empowers patients to engage and contribute more effectively in the development and approval of new treatments and become true partners in pharmaceutical R\&D. A challenge is now to ensure that these resources are sustained on a longer term than through projects, maintaining excellence in the services provided and the underlying science.

\section{Conclusion}

The current second edition of IMI, IMI2, will launch calls for proposals until end 2020, and will formally run until 31 December 2024, with some of the funded projects likely to continue their activities beyond 2024. The coming calls for proposals until 2020 should see the development of additional large-scale initiatives in areas the Founding Members agree are priorities: immunology, anti-microbial resistance, the modernisation of clinical trials and regulatory pathways, and digital health and big data. Considering the results of the interim evaluation of IMI2, and the evolution of medicines development, the remaining period of IMI 2 should focus on innovative cross-sectoral approaches, and should involve more deeply non-pharmaceutical companies and other nonpharma stakeholders. The programmes and projects still to come under IMI2 should further strengthen the important legacy of achievement from this unique public-private collaboration in health research. It will, however, be important, in the coming years, to fully measure and capture the overall impact of the initiative, beyond the project results and success stories as exemplified in this article.

Acknowledgements We thank Hazel Collier and Elmar Nimmesgern for carefully reading the article.

\section{Compliance with Ethical Standards}

Funding No funding sources were used to assist with the preparation of this manuscript. Costs for ensuring Open Access to this article have been covered by the European Commission.

Conflicts of interest Irene Norstedt is a member of the Innovative Medicines Initiative Governing Board, representing the European Commission, and Line Matthiessen has been member until 30 June 2018. Tomasz Dylagg and Jean-Emmanuel Faure are observers at the
Innovative Medicines Initiative Governing Board meetings, representing the European Commission.

Open Access This article is distributed under the terms of the Creative Commons Attribution-NonCommercial 4.0 International License (http://creativecommons.org/licenses/by-nc/4.0/), which permits any noncommercial use, distribution, and reproduction in any medium, provided you give appropriate credit to the original author(s) and the source, provide a link to the Creative Commons license, and indicate if changes were made.

\section{References}

1. EU Research \& Innovation Participant Portal. http://ec.europa.eu/ research/participants/portal/desktop/en/opportunities/index.html. Accessed 30 June 2018.

2. Regulation (EU) No 1291/2013 of the European Parliament and of the Council of 11 December 2013 establishing Horizon 2020 - the Framework Programme for Research and Innovation (2014-2020) and repealing Decision No 1982/2006/EC. Official Journal of the European Union, L 347 of 20.12.2013, pp. 104-173. http:// ec.europa.eu/research/participants/data/ref/h2020/legal_basis/fp/ h2020-eu-establact_en.pdf. Accessed 30 June 2018.

3. Council Regulation (EC) No 73/2008 of 20 December 2007 setting up the Joint Undertaking for the implementation of the Joint Technology Initiative on Innovative Medicines, Official Journal of the European Union, L 30, 04.02.2008, pp. 38-51. https:// publications.europa.eu/en/publication-detail/-/publication/d6e3e 98f-5eae-43db-90f8-6004a2519da4. Accessed 30 June 2018.

4. Council Regulation (EU) No 557/2014 of 6 May 2014 establishing the Innovative Medicines Initiative 2 Joint Undertaking, Official Journal of the European Union, L 169, 07.06.2014, pp. 54-76. http://eur-lex.europa.eu/legal-content/EN/TXT/?uri=celex \%3A32014R0557. Accessed 30 June 2018.

5. Innovative Medicines Initiative: website. http://www.imi.europ a.eu. Accessed 30 June 2018.

6. Innovative Medicines Initiative: List of Associated Partners. http:// www.imi.europa.eu/get-involved/associated-partners, http://www. who.int/medicines/areas/priority_medicines/MasterDocJune28 _FINAL_Web.pdf. Accessed 30 June 2018.

7. The right prevention and treatment for the right patient at the right time. Strategic Research Agenda for Innovative Medicines Initiative 2. http://www.imi.europa.eu/sites/default/files/uploads/ documents/About-IMI/research-agenda/IMI2_SRA_March2014. pdf. Accessed 30 June 2018.

8. Kaplan W, Wirtz VJ, Mantel-Teeuwisse A, Stolk P, Duthey B, Laing R. Priority medicines for Europe and the World 2013 update. World Health Organization. 2013. ISBN 978-92-4-150575-8.

9. Innovative Medicines Initiative: Strategic Governance Groups. http://www.imi.europa.eu/about-imi/governance/strategic-gover ning-groups. Accessed 30 June 2018.

10. Expert Group. The final evaluation of the innovative medicines initiative joint undertaking (2008-2016) operating under the 7th Framework Programme. Luxembourg: Publications Office of the European Union; 2017. https://doi.org/10.2777/72723. ISBN 978-92-79-69295-6.

11. Expert Group. The Interim Evaluation of the Innovative Medicines Initiative 2 Joint Undertaking (2014-2016) operating under Horizon 2020. Luxembourg: Publications Office of the European Union; 2017. https://doi.org/10.2777/173999. ISBN 978-92-79-69299-4. 
12. European Commission, 6.10.2017 SWD(2017) 339 final, Commission staff working document: Interim evaluation of the Joint Undertakings operating under Horizon 2020. https:// ec.europa.eu/research/evaluations/pdf/20171009_a187_swd. pdf\#view $=$ fit\&pagemode $=$ none. Accessed 30 June 2018.

13. Innovative Medicines Initiative: Bibliometric analysis of ongoing projects, 8th report. 2017. http://www.imi.europa.eu/sites/defau lt/files/uploads/documents/reference-documents/IMI_Publicatio nAnalysis_2017.pdf. Accessed 30 June 2018.

14. Innovative Medicines Initiative. Carrying the torch for medical innovation. 2017. http://www.imi.europa.eu/sites/default/files/ news/Brochure_ResultsImpact.pdf. Accessed 30 June 2018.

15. IMI eTOX project: Integrating bioinformatics and chemo-informatics approaches for the development of Expert systems allowing the in silico prediction of toxicities. http://www.e-tox.net. Accessed 30 June 2018.

16. Sanz F, Pognan F, Steger-Hartmann T, Díaz C; eTOX, Cases M, Pastor M, et al. Legacy data sharing to improve drug safety assessment: the eTOX project. Nat Rev Drug Discov. 2017;16:811-2. https://doi.org/10.1038/nrd.2017.177.

17. IMI SAFE-T project: safer and faster evidence-based translation. http://www.imi-safe-t.eu. Accessed 30 June 2018.

18. IMI PRO-Active project: physical activity as a crucial patient reported outcome in COPD. http://www.imi.europa.eu/projectsresults/project-factsheets/pro-active. Accessed 30 June 2018.

19. Zuidgeest MGP, Goetz I, Groenwold RHH, Irving E, van Thiel GJMW, Grobbee DE, et al. Series: Pragmatic trials and real world evidence: Paper 1. Introduction. J Clin Epidemiol. 2017;88:7-13; https://doi.org/10.1016/j.jclinepi.2016.12.023 and the following papers 2-8: http://www.jclinepi.com/content/jce-Pragmatic_Trial s_and_Real_World_Evidence. Accessed 30 June 2018.

20. Makady A, Stegenga H, Ciaglia A, Debray TP, Lees M, Happich M, et al. Practical implications of using real-world evidence (RWE) in comparative effectiveness research: learnings from IMIGetReal. J Comp Eff Res. 2017;6:485-90. https://doi.org/10.2217/ cer-2017-0044.

21. IMI ADAPT-SMART project: Accelerated development of appropriate patient therapies: a sustainable, multi-stakeholder approach from research to treatment-outcomes. http://www.adaptsmart.eu. Accessed 30 June 2018.

22. IMI RADAR-CNS project: remote assessment of disease and relapse in central nervous system disorders. http://www.radar-cns. org. Accessed 30 June 2018.

23. IMI PRECISESADS project: Molecular reclassification to find clinically useful biomarkers for systemic autoimmune diseases. http://www.precisesads.eu. Accessed 30 June 2018.

24. IMI AETIONOMY project: Organising mechanistic knowledge about neurodegenerative diseases for the improvement of drug development and therapy. http://www.aetionomy.eu. Accessed 30 June 2018.

25. Hofmann-Apitius M, Alarcón-Riquelme ME, Chamberlain C, McHale D. Towards the taxonomy of human disease. Nature Rev Drug Discov. 2015;14:75-6. https://doi.org/10.1038/nrd4537.

26. IMI EU-AIMS project: European Autism Interventions-a multicentre study for developing new medications. http://www.eu-aims. eu. Accessed 30 June 2018.

27. Kong A, Frigge ML, Masson G, Besenbacher S, Sulem P, Magnusson $\mathrm{G}$, et al. Rate of de novo mutations and the importance of father's age to disease risk. Nature. 2012;488:471-5. https://doi. org/10.1038/nature11396.

28. Poulopoulos A, Soykan T, Tuffy LP, Hammer M, Varoqueaux F, Brose N. Homodimerization and isoform-specific heterodimerization of neuroligins. Biochem J. 2012;446:321-30. https://doi.org/10.1042/BJ20120808.

29. Lai MC, Lombardo MV, Suckling J, Ruigrok AN, Chakrabarti B, Ecker C, et al. Biological sex affects the neurobiology of autism. Brain. 2013;136:2799-815. https://doi.org/10.1093/brain/awt216.

30. Bourgeron T. From the genetic architecture to synaptic plasticity in autism spectrum disorder. Nat Rev Neurosci. 2015;16:551-63. https://doi.org/10.1038/nrn3992.

31. Loth E, Spooren W. Murphy DG, for the EU-AIMS consortium. New treatment targets for autism spectrum disorders: EU-AIMS. Lancet Psychiatry. 2014;1:413-5. https://doi.org/10.1016/S2215 -0366(14)00004-2.

32. Loth E, Charman T, Mason L, Tillmann J, Jones EJH, Wooldridge $\mathrm{C}$, et al. The EU-AIMS Longitudinal European Autism Project (LEAP): design and methodologies to identify and validate stratification biomarkers for autism spectrum disorders. Mol Autism. 2017;8:24. https://doi.org/10.1186/s13229-017-0146-8.

33. Charman T, Loth E, Tillmann J, Crawley D, Wooldridge C, Goyard D, et al. The EU-AIMS Longitudinal European Autism Project (LEAP): clinical characterisation. Mol Autism. 2017;8:27. https://doi.org/10.1186/s13229-017-0145-9.

34. IMI U-BIOPRED project: Unbiased biomarkers for the prediction of respiratory disease outcomes. http://www.europeanlung.org/en/ projects-and-research/projects/u-biopred/home.

35. Fleming L, Murray C, Bansal AT, Hashimoto S, Bisgaard H, Bush A, et al. The burden of severe asthma in childhood and adolescence: results from the paediatric U-BIOPRED cohorts. Eur Respir J. 2015;46:1322-33. https://doi.org/10.1183/13993 003.00780-2015.

36. Editorial: a new identity for asthma. Lancet Respir Med. 2015;3:735. https://doi.org/10.1016/S2213-2600(15)00369-0.

37. Hekking PP, Loza MJ, Pavlidis S, De Meulder B, Lefaudeux $\mathrm{D}$, Baribaud F, et al. Transcriptomic gene signatures associated with persistent airflow limitation in patients with severe asthma. Eur Respir J. 2017;50:1602298. https://doi.org/10.1183/13993 003.02298-2016.

38. Bigler J, Boedigheimer M, Schofield JPR, Skipp PJ, Corfield $\mathrm{J}$, Rowe A, et al. A severe asthma disease signature from gene expression profiling of peripheral blood from U-BIOPRED cohorts. Am J Respir Crit Care Med. 2017;195:1311-20. https:// doi.org/10.1164/rccm.201604-0866OC.

39. IMI EBOVAC1 and EBOVAC2 projects: Development of a prophylactic Ebola vaccine using an heterologous prime-boost regimen. http://www.ebovac.org. Accessed 30 June 2018.

40. Winslow RL, Milligan ID, Voysey M, Luhn K, Shukarev G, Douoguih M, et al. Immune responses to novel adenovirus type 26 and modified vaccinia virus Ankara-vectored Ebola vaccines at 1 year. JAMA. 2017;317:1075-7. https://doi.org/10.1001/ jama.2016.20644.

41. IMI Mofina project: Mobile Filovirus Nucleic Acid Test. http:// www.imi.europa.eu/projects-results/project-factsheets/mofina. Accessed 30 June 2018.

42. IMI ELF project: European Lead Factory. http://www.europeanle adfactory.eu. Accessed 30 June 2018.

43. Besnard J, Jones PS, Hopkins AL, Pannifer AD. The Joint European Compound Library: boosting precompetitive research. Drug Discov Today. 2015;20:181-6. https://doi.org/10.1016/j.drudi s.2014.08.014.

44. IMI COMBACTE-NET project: Combatting Bacterial Resistance in Europe. http://www.combacte.com. Accessed 30 June 2018.

45. IMI EUPATI project: European Patients' Academy on Therapeutic Innovation. http://www.eupati.eu. Accessed 30 June 2018. 